\title{
Features of diamond from some deposits of Siberia revealed by FTIR
}

\author{
I.N. Bogush ${ }^{1}$, E.A. Vasilyev ${ }^{2}$ \\ ${ }^{1}$ ALROSA Co. Ltd, Mirny, Russia, ${ }^{2}$ Saint-Petersburg State Mining Institute, Saint-Petersburg, Russia
}

Introduction: Measurement of absorption spectra in IR range for definition of concentration of structural defects $\mathrm{A}, \mathrm{B} 1$, and $\mathrm{B} 2$ is one of the ways of revealing specific features of diamonds from various sources (Kaminsky et al., 2001). According to present-day understanding A defect consists of two atoms of nitrogen (Davies, 1976), and B1 from four atoms of nitrogen and vacancy (Bursill, Glaisher, 1985). B1 defect emerges from two A defects during formation and interstitial atoms of carbon appear of which more complicated centers B2 - «platelets» (Allen, Evans, 1981; Goss et al., 2003) are formed further. We have defined concentration of nitrogen in $\mathrm{A}$ and $\mathrm{B} 1$ forms, absorbance and maximum position of band $\mathrm{B} 2$ in diamonds from kimberlite pipes of different regions of the Siberian platform. The purpose of operation was revealing parameters for more reliable identification of placer diamonds' primary sources.

Specimens and methods: Samples of $-4+1 \mathrm{~mm}$ size from pipe Mir (603 pieces) and located in $16 \mathrm{~km}$ away from it pipe International (726 pieces) of MaloBotuobinsky diamondiferous region; from kimberlite bodies Nyurbinskaya (1282 pieces) and Botuobinskaya (190 pieces) of Srednemarkhinsky region, with $3 \mathrm{~km}$ distance between them; from pipe Zapolyarnaya (1197 pieces) of Verkhnemunsky region were selected for research. Spectra were recorded on FTIR spectrometer FSM-1201 in the range of $400-4000 \mathrm{sm}^{-1}$ with $4 \mathrm{sm}^{-1}$ resolution across natural facets of diamonds. Concentrations of nitrogen in the form of $\mathrm{A}$ and B1 defects were computed according to (Bokiy G.B. et al., 1986; Boyd et al., 1994; Boyd et al. 1995). The size of B2 defects was defined on the position of band maximum (Sobolev et al., 1968).

Results: Octahedrons and individuals with sheaflike hatching on ribs and with polycentric structure dominate in pipes Mir, International, Botuobinskaya and Nyurbinskaya. Collection from pipe Zapolyarnaya is represented mainly by rhombic dodecahedrons. There are many individuals with splintery hatching, thin-and cryptolayered, with shagreen and bands of plastic deformation.

Both nitrogen-free crystals and individuals with more than 2000 at. ppm concentration of nitrogen have been revealed in each deposit. Concentration of nitrogen at this in various by structure of facets diamonds noticeably differ. But contents of nitrogen for crystals of specific habit and structure of facets from various sources are similar. Table-cut octahedrons are most high-nitrogen for analyzed deposits - mainly from 500 up to 1250 at. ppm (fig. 1, a). There is less nitrogen in individuals with sheaf-like hatching, with block sculpture, polycentric structure of facets. Most low-nitrogen group of diamonds is that with splintery hatching, thin-layered, with shagreen and bands of plastic deformation (less than 700 at. ppm) (fig. 1, b).

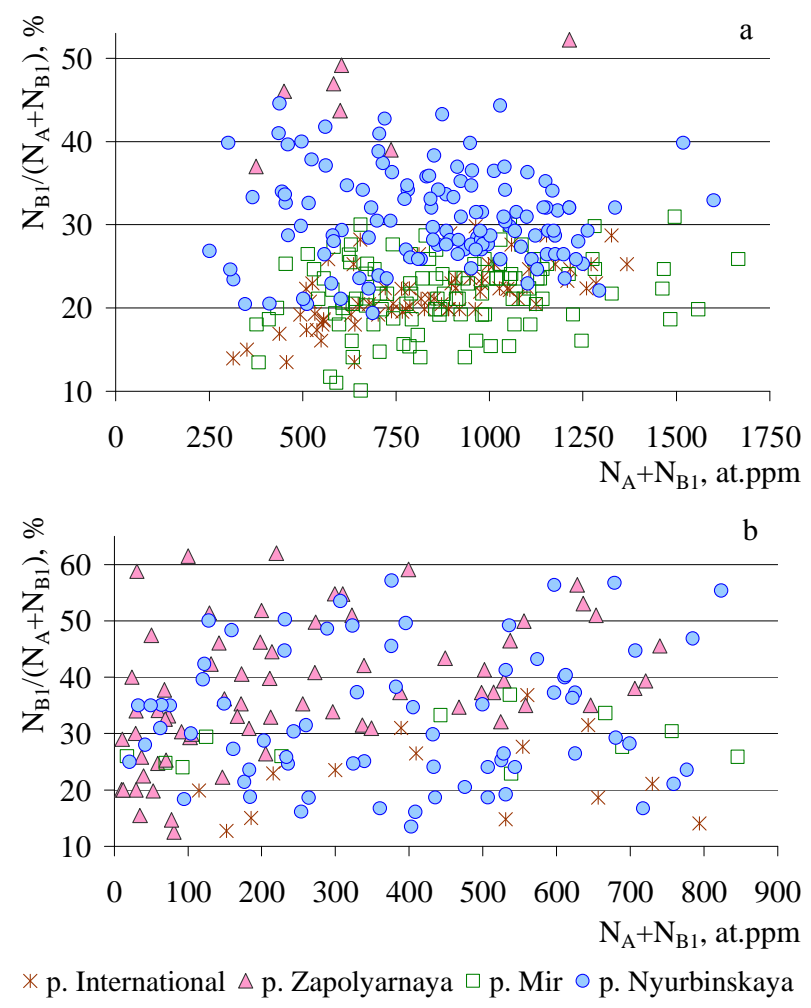

Fig. 1 Content of nitrogen and its percent in B-form in table-cut octahedrons (a) and octahedrons with splintery hatching (b) from kimberlite pipes of the Siberian platform

Diamonds of kimberlite pipes somewhat differ by percentage of nitrogen in B-form (see fig. 1). Aggregation stage of nitrogen in diamonds from pipe Zapolyarnaya is big - on average from 35 up to $50 \%$ for each group of individuals analyzed on morphology. Averaged values of nitrogen percentage in B-form are 
very low for crystals of pipe Botuobinskaya - from 15 up to $30 \%$, and for diamonds of nearby pipe Nyurbinskaya this parameter for different groups is higher - from 20 up to $35 \%$. Aggregation stage of nitrogen in diamonds from pipes Mir and International is similar.

The greatest difference of crystals from the deposits is noted on characteristics of B2-center. Figure 2 demonstrates the position of diamonds of analyzed groups on diagram "absorbance of B2-size B2".

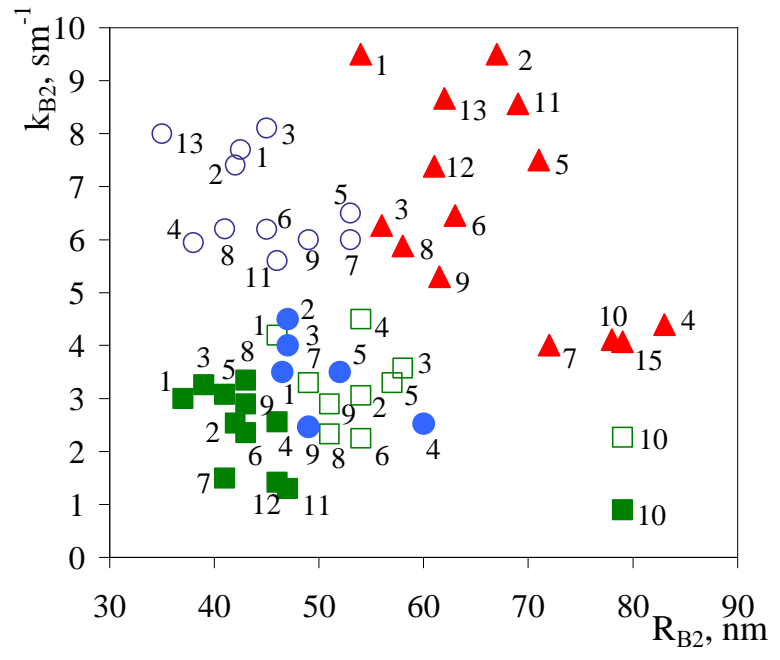

$\square$ - Mir, $\square$ - International, •- Botuobinskaya,

O- Nyurbinskaya, $\boldsymbol{\Delta}$ - Zapolyarnaya

Fig. 2 Position of diamonds from kimberlite pipes of the Siberian platform on diagram "absorbance of B2-size B2"

Octahedrons: table-cut - 1, with trigonal layers of growth - 2, with sheaf-like hatching - 3, ditrigonal with splintery hatching -4 , with polycentric facets -5 ;

crystals of transient forms from octahedron to rhombic dodecahedron: with sheaf-like hatching - 6, with splintery hatching -7 , with block sculpture -8 , with polycentric growth of facets - 9;

laminar rhombic dodecahedrons: thin-layered - 10, with block sculpture - 11;

dodecahedroids: hidden-layered - 12, with sheaf-like hatching - 13, with block sculpture - 14, with shagreen and bands of plastic deformation - 15

Diamonds with various morphology from pipe International on averaged values of B2-centers are located compactly. The least size and absorbance of "platelets" are characteristic of them. The majority of diamonds from pipe Mir has the mean of band B2 absorptance and the size of these defects is more than in those from pipe International. Crystals of the selected groups from pipes of Srednemarkhinsky region differ slightly by average sizes of B2-defects, but individuals of pipe Nyurbinskaya are characterized by higher averaged values of B2 absorbance. Diamonds of these closely located deposits occupy isolated position on this diagram. Greater factors and sizes of B2-centers are noted in diamonds of primary body of Verkhnemunsky region. Their position is individual.
Carried out research allowed to reveal similar concentration of nitrogen in crystals with similar facet morphology from various regions' deposits of the Siberian platform. It is not easy to identify the primary source of crystals by general content of nitrogen. Similar morphological spectra of crystals, contents of total nitrogen in them show that diamonds of pipes Mir and International, Botuobinskaya and Nyurbinskaya grew in very similar conditions. Diamonds of these diamondiferous regions differ by aggregation of nitrogen and B2-centers, and the average parameters of B2 absorption bands are various for crystals from nearby kimberlite bodies with similar diamonds on morphology and general content of nitrogen, its aggregation. Average values of absorbance and maxima of B2 position of absorption bands (platelets) at this, have not only maximum differences for specimens of diamonds from various sources, but also minimal spreads for various specimens from one source. Kinetic parameters and formation of these defects are not studied sufficiently and we suppose that they are formed through intermediate stages and are the result of complex effect of general concentration of nitrogen, temperature of growth and post-growth conditions. Diamonds of located closely kimberlite pipes Mir and International, Botuobinskaya and Nyurbinskaya have different characteristics' values of «platelets». Hence, these characteristics are defined by spatially localized processes. Aggregation of nitrogen, concentration and size of B2-centers allow to reveal differences of diamonds not only from different regions, but also from a one kimberlite field and can be used for solution of different in rank diamondprospecting tasks.

\section{References:}

Allen B.P., Evans T., 1981. Aggregation of nitrogen in diamond, including platelet formation. Proc. R. Soc. Lond A, 375, 93-104.

Bokiy G.B. et al., 1986. Natural and synthetic diamonds. Moscow: Science, $222 \mathrm{p}$.

Boyd S. R. et al., 1994. The relationship between infrared absorption and the A defect concentration in diamond. Philosophical Magazine B, 69, 1149-1153.

Boyd S. R. etc., 1995. Infrared absorption by the B nitrogen aggregate in diamond. Philosophical Magazine B, 72, 351361 .

Bursill L.A., Glaisher R.W., 1985. Aggregation and dissolution of small and extended defect structures in type Ia diamond. Amer. Miner., 70, 608-618.

Davies G., 1976. The A nitrogen aggregate in diamond - its symmetry and possible structure. J. Phys. C: Solid State Phys., 9, 537-542.

Goss J.P. et al., 2003. Extended defects in diamond: the interstitial platelet. Physical Review B, 67, 165208.

Kaminsky F.V., Khachatryan G.K., 2001. Characteristics of nitrogen and other impurities in diamond, as revealed by infrared absorption data. Canad. Mineralogist, 39, 17331745.

Sobolev E.V. et al., 1968. About lamellar formations in structure of natural diamonds. Structural Chemistry Magazine, 6, 1029-1033. 